\title{
Color Stability of Modern Composites Subjected to Different Periods of Accelerated Artificial Aging
}

\author{
Brahim DRUBI-FILHO \\ Lucas da Fonseca Roberti GARCIA \\ Diogo Rodrigues CRUVINEL \\ Ana Beatriz Silva SOUSA \\ Fernanda de Carvalho Panzeri PIRES-DE-SOUZA \\ Department of Dental Materials and Prosthodontics, Ribeirão Preto Dental School, \\ USP - University of São Paulo, Ribeirão Preto, SP, Brazil
}

\begin{abstract}
The aim of this study was to evaluate the color stability of composites subjected to different periods of accelerated artificial aging (AAA). A polytetrafluorethylene matrix $(10 \times 2 \mathrm{~mm})$ was used to fabricate 24 test specimens of three different composites ( $\mathrm{n}=8)$ : Tetric Ceram (Ivoclar/Vivadent); Filtek P90 and Z250 (3M ESPE), shade A3. After light activation for $20 \mathrm{~s}$ (FlashLite 1401), polishing and initial color readout (Spectrophotometer PCB 687; BYK Gardner), the test specimens were subjected to AAA (C-UV; Comexim), in 8-h cycles: $4 \mathrm{~h}$ exposure to UV-B rays at $50^{\circ} \mathrm{C}$ and $4 \mathrm{~h}$ condensation at $50^{\circ} \mathrm{C}$. At the end of each cycle, color readouts were taken and the test ended when the mean value of $\Delta \mathrm{E}$ attained a level $\geq 3.30$. Tetric Ceram presented alteration in $\Delta \mathrm{E}$ equal to 3.33 in the first aging cycle. For Filtek P90 and Z250, two $(\Delta \mathrm{E}=3.60)$ and four $(\Delta \mathrm{E}=3.42)$ AAA cycles were necessary. After each cycle, there was a reduction of luminosity in all the samples $(\Delta \mathrm{L})$. It was concluded that a short period of AAA was sufficient to promote clinically unacceptable color alteration in composites, and that this alteration was material-dependent.
\end{abstract}

Key Words: composites, color stability, aging, silorane.

\section{INTRODUCTION}

Composites are widely used in dental practice, due to their mechanical and optical properties that allow the dentist to make restorations that resemble the dental structure (1).

Several types of composites are currently available in the market, from microhybrid and nanoparticle-filled materials, to modern silorane-based composites (1). Silorane-based composites represent a new class of dental composites obtained from the reaction of oxirane and siloxane molecules, which provide these materials with some advantages in relation to the methacrylatebased ones: low rates of polymerization shrinkage due to the oxirane ring-opening during polymerization reaction (2) and increase of hydrophobicity, making the material insoluble in water (2). Nevertheless, the greatest challenge continues to be promoting and maintaining the exact color between the tooth and restoration (3).
Therefore, color alteration of these materials is the major cause of restoration replacement in anterior teeth (3).

Composite color alteration is multifactorial and is associated with intrinsic discoloration and extrinsic staining of the material. Intrinsic factors are related to the chemical stability of the resinous matrix and the matrix/particle interface (3), while the extrinsic factors are related to the absorption of staining solutions by the material, due to the patient's dietary, hygiene and smoking habits (4).

The affinity of the composite for substances that cause staining is modulated by its degree of conversion and its chemical characteristics (5). The larger the number of unconverted double carbon bonds, the more susceptible the material is to staining (6). In addition, composites with hydrophilic organic matrices favor water absorption, promoting degradation of the polymeric network, which results in the release of byproducts, such as formaldehyde and methacrylic acid 
$(7,8)$, and consequently, color alteration (3).

The "useful life" of a restorative material begins right after its application in the patient's oral cavity (6). Although it may be possible to evaluate color and other parameters related to esthetics immediately, it is difficult to verify these properties in the long term (9) due to the rapid development and release of new products on the market, which turns impossible to conduct longitudinal clinical studies (8).

Physicochemical actions, such as visible light and ultraviolet (UV) irradiation, temperature and humidity, promote intrinsic color alteration in composites over the course of time (10). Therefore, artificial aging methods have been used for years as instruments to predict, within a short time, possible alterations in the mechanical and optical properties of composites $(3,8,11)$. Accelerated artificial aging (AAA) consists of submitting restorative materials, among them composites, to long intervals of exposure to UV-B rays, humidity and sudden alterations in temperature. Exposure of the composite to these phenomena promotes alterations in its organic matrix, the main factor responsible for color alteration of the material over the course of time (12).

Several studies have evaluated the mechanical and optical behavior of composites after artificial aging. Nevertheless, comparison of studies in which composites are subjected to AAA is difficult, since different methods and periods of aging are employed (1,11-13).

There is no standardization regarding the aging time necessary for promoting color alteration in composites after AAA. According to Pires-de-Souza et al. (13), $300 \mathrm{~h}$ of AAA correspond to approximately 1 year of clinical use; however, it is not clear at which moment of the aging procedure composites present color alteration above the clinically acceptable limit (14). Furthermore, little evidence is available regarding the aging behavior of modern composites, such as silorane-based ones. Thus, the aim of this study was to evaluate the color stability of composites subjected to different periods of AAA. The tested hypothesis was that aging time has influence on the optical properties of composites.

\section{MATERIAL AND METHODS}

\section{Test Specimen Fabrication}

The composites used in this study are described in Table 1.

Twenty-four test specimens were fabricated $(\mathrm{n}=8)$ using a polytetrafluorethylene matrix $(2 \mathrm{~mm} \mathrm{x}$ $10 \mathrm{~mm}$ ) by the incremental technique and pressure was placed on the last increment covered with a glass slide to prevent oxygen inhibition. The samples were light activated with a LED device (FlashLite 1401; Discus Dental, Culver City, CA, USA) light intensity $\geq 1,100$ $\mathrm{mW} / \mathrm{cm}^{2}$ and wavelength in the band between 460 and $480 \mathrm{~nm}$, for $20 \mathrm{~s}$, in accordance with the manufacturer's recommendations. After this, the specimens were polished onto 320-, 600-, and 1200-grit wet abrasive papers (Norton, São Paulo, SP, Brazil), had their final thickness measured with a digital caliper (Digimess; Shinko Precision, Gaging, China), and were coded and stored at $37^{\circ} \mathrm{C}$ protected from light until being subjected to color analysis (Spectrophotometer PCB 6807; BYKGardner, Geretsried, Germany).

Table 1. Composites used in the study.

\begin{tabular}{|c|c|c|c|c|}
\hline Composite & Composition & $\begin{array}{l}\text { Filler mean } \\
\text { size }\end{array}$ & $\begin{array}{c}\text { Filler \% } \\
\text { (by volume) }\end{array}$ & Manufacturer \\
\hline Filtek P90 & $\begin{array}{l}\text { BIS-3,4-epoxycyclohexylethyl-phenyl-methylsilane, } \\
\text { 3,4-epoxycyclohexylethyl-cyclopolymethylsiloxane, di-and epoxy- } \\
\text { functional oligosiloxane, trifluoride ITRE, quartz fillers. }\end{array}$ & $0.1-2 \mu \mathrm{m}$ & $55 \%$ & $\begin{array}{l}\text { 3M ESPE, St. } \\
\text { Paul, MN, USA }\end{array}$ \\
\hline $\begin{array}{l}\text { Tetric } \\
\text { Ceram }\end{array}$ & $\begin{array}{l}\text { Bis-GMA, UDMA, TEGDMA, Aluminum-silicate glass and } \\
\text { silanized Barium glass, Silicon, } \mathrm{YbF}_{3}, \mathrm{CQ} \text {, Mineral Pigments. }\end{array}$ & $0.2-1.0 \mu \mathrm{m}$ & $78.6 \%$ & $\begin{array}{c}\text { Ivoclar/ } \\
\text { Vivadent } \\
\text { AG, Schaan, } \\
\text { Liechtenstein }\end{array}$ \\
\hline $\mathrm{Z} 250$ & BIS-GMA, UDMA, BIS-EMA, silica/zirconium inorganic fillers. & $0.01-3.5 \mu \mathrm{m}$ & $60 \%$ & $\begin{array}{l}\text { 3M ESPE, St. } \\
\text { Paul, MN, USA }\end{array}$ \\
\hline
\end{tabular}

Bis-GMA: Bisphenol-A-glycidyl dimethacrylate. UDMA: Urethane dimethacrylate. Bis-EMA: Bisphenol A ethoxylate dimethacrylate. TEGDMA: Triethylene glycol dimethacrylate, HEMA: 2-Hydroxyethyl methacrylate. CQ: Camphorquinone. 


\section{Color Stability Analysis}

The observation pattern simulated by the spectrophotometer followed the CIE L*a*b* system, recommended by CIE (Commission Internationale de l'Éclairage). This consists of two perpendicular axes, $\mathrm{a}^{*}$ and $\mathrm{b}^{*}$, and represent the dimension of tonality or color. The third axis is luminosity $\mathrm{L}^{*}$, which is perpendicular to the $a^{*} b^{*}$ plane. With this system, colors can be specified with the coordinates $\mathrm{L}^{*}, \mathrm{a}^{*}$ and $b^{*}$. For color readout, the test specimens were initially placed on a block with a standard white background (White Standard Sphere for $45^{\circ} / 0^{\circ}$; Reflectance and Color Gardner Laboratory Inc., Bethesda, Geretsried, Germany) coupled to the spectrophotometer, and when activated, 30 LED lamps of 10 different colors disposed in a circular arrangement light up with the light beam incident on the material surface at a $45^{\circ}$ angle, using the primary standard illuminant D65, which simulates the spectrum of natural daylight. This beam is reflected back at $0^{\circ}$, capturing and recording the values of $\mathrm{L}^{*}, \mathrm{a}^{*}$ and $b^{*}$ of each test specimen.

After the initial color read out, the test specimens were subjected to AAA cycles in order to evaluate color stability. The AAA system for non-metallic materials C-UV (Comexim Matérias Primas Ind. e Com. Ltda., São Paulo, SP, Brazil) simulates the forces of nature predicting the relative durability of materials exposed to an inclement environment. The test specimens were

Table 2. Mean values (standard deviation) of $\Delta \mathrm{L}, \Delta \mathrm{a}, \Delta \mathrm{b}$ and $\Delta \mathrm{E}$ for the composites evaluated after each AAA cycle.

\begin{tabular}{|c|c|c|c|c|c|}
\hline Composite & Cycle & $\Delta \mathrm{L}$ & $\Delta \mathrm{a}$ & $\Delta \mathrm{b}$ & $\Delta \mathrm{E}$ \\
\hline $\begin{array}{l}\text { Tetric } \\
\text { Ceram }\end{array}$ & 1 & $-0.38(0.13)$ & $-0.55(0.11)$ & $3.25(0.53)$ & $3.33(0.51)$ \\
\hline \multirow{2}{*}{ P90 } & 1 & $-1.11(0.46)$ & $1.12(0.15)$ & $2.59(0.29)$ & $3.06(0.36)$ \\
\hline & 2 & $-1.37(0.39)$ & $1.35(0.20)$ & $3.01(0.51)$ & $3.60(0.50)$ \\
\hline \multirow{4}{*}{$\mathrm{Z} 250$} & 1 & $-1.11(0.47)$ & $0.04(0.12)$ & $0.62(0.72)$ & $1.38(0.66)$ \\
\hline & 2 & $-2.57(0.60)$ & $0.05(0.23)$ & $1.24(1.50)$ & $3.21(0.48)$ \\
\hline & 3 & $-2.28(0.39)$ & $0.24(0.28)$ & 1.09 (1.59) & $2.94(0.53)$ \\
\hline & 4 & $-2.56(0.65)$ & $0.49(0.24)$ & $1.04(2.06)$ & $3.43(0.62)$ \\
\hline
\end{tabular}

fixed to the plates of the appliance and taken to the condensation chamber facing a light source at a distance of $50 \mathrm{~mm}$. The functioning program was set for $4 \mathrm{~h}$ of exposure to ultraviolet rays (UV-B) at $50^{\circ} \mathrm{C}$ and $4 \mathrm{~h}$ of condensation at $50^{\circ} \mathrm{C}$. The maximum aging time for each cycle was $8 \mathrm{~h}$, in order to determine at what time interval the material would present color alteration above the clinically accepted level $(\Delta \mathrm{E} \geq 3.30)(15)$. At the end of each cycle, new color readout was taken. The color stability of the materials was determined by the difference $(\Delta \mathrm{E})$ between the coordinates obtained from the samples at baseline and after each AAA cycle. $\Delta \mathrm{E}$ was calculated by the following equation:

$$
\Delta \mathrm{E}=\left[(\Delta \mathrm{L})^{2}+(\Delta \mathrm{a})^{2}+(\Delta \mathrm{b})^{2}\right]^{1 / 2}
$$

where, $\Delta \mathrm{L}=: \mathrm{L}_{2}-\mathrm{L}_{1} ; \Delta \mathrm{a}=\mathrm{a}_{2}-\mathrm{a}_{1} ; \Delta \mathrm{b}=\mathrm{b}_{2}-\mathrm{b}_{1}$. The subscript number 2 corresponds to the readout after AAA and subscript number 1 to the initial readout (13). $\Delta \mathrm{L}$ is the difference in luminosity, $\Delta \mathrm{a}$ is the difference in the red-green parameter $\left(-a^{*}=\right.$ green $\mathrm{e}+\mathrm{a}^{*}=$ red $)$ and $\Delta \mathrm{b}$ is the difference in the yellow-blue parameter $\left(-\mathrm{b}^{*}\right.$ $=$ blue $\mathrm{e}+\mathrm{b}^{*}=$ yellow) (13). After each analysis, the mean values for color stability were noted, and when they attained the value of $\Delta \mathrm{E} \geq 3.30$, the cycle was ended.

\section{RESULTS}

Table 2 presents the mean values for $\Delta \mathrm{L}, \Delta \mathrm{a}, \Delta \mathrm{b}$, and $\Delta \mathrm{E}$ for each composite.

Tetric Ceram, after the first 8-h aging cycle presented a $\Delta \mathrm{E}$ mean value of 3.33 , which is above the clinically acceptable limit. For Filtek P90, two 8-h AAA cycles were necessary for the $\Delta \mathrm{E}$ mean to attain a value above the clinically acceptable limit $(\Delta \mathrm{E}=3.60)$. Z250 composite was the one that required the highest number of AAA cycles (four) for the $\Delta \mathrm{E}$ mean to attain a level above the clinically accepted value $(\Delta \mathrm{E}=3.43)$.

Comparing $\Delta \mathrm{L}$ among the studied composites, there was a reduction in the values of $L^{*}$ after aging, which is reflected in negative values for $\Delta \mathrm{L}$, demonstrating loss of luminosity after AAA cycles. When the 
variation of the coordinate $\mathrm{a}^{*}(\Delta \mathrm{a})$ was compared, Tetric Ceram presented a tendency towards a green tonality after the first AAA cycle (-0.55), whereas Filtek P90 tended towards red, which became accentuated in the second cycle (1.35). Z250 remained practically stable irrespective of the number of AAA cycles.

When the variation of coordinate $b^{*}(\Delta b)$ was compared, it was verified that all the composites presented a trend towards yellow, more accentuated for Tetric Ceram (3.25), followed by composite Filtek P90 (3.01). The least alteration in this coordinate occurred for Tetric Ceram, whose maximum $\Delta \mathrm{b}$ value reached 1.24 after two AAA cycles, and remained at 1.04 after attaining clinically unacceptable levels of $\Delta \mathrm{E}$.

\section{DISCUSSION}

Several studies refer to the effects of AAA on the color stability of dental materials $(3,8,11,13)$. In spite of the differences among the materials, these studies use non-standard equipment and methodologies for aging, which results in conflicting findings among them. Thus, there is no consensus among researchers about the length of AAA time that is equivalent to a certain period of clinical use of a composite restoration $(11,15)$.

Ferracane et al. (10) verified that, in the oral environment, composites present degradation of the surface and subsurface of the material, generating microfractures through which staining substances can penetrate (16). Several studies that have evaluated longterm alterations of the mechanical and optical properties of composites, used equipment able of promoting such alterations in a short period of time $(10,11)$. Generally, the aging cycles used are predetermined according to the directions of the manufacturer of each aging equipment $(13,15)$. However, it is not known at which moment in artificial aging the material begins to degrade and present alterations in its properties. According to Hahnel et al. (1), artificial aging leads to a significant decrease on dental composite properties. Moreover, the aging time promotes further degradation than the aging medium.

The AAA cycles applied in this study $(8 \mathrm{~h})$ were the shortest possible so that one could determine, as precisely as possible, at which moment the material would present color alteration above the clinically acceptable level $(\Delta \mathrm{E} \geq 3.30)$. This value was initially suggested by Ruyter et al. (14), according to whom, the color alteration of a restoration became perceptible to the naked eye. Many studies use this value as a standard for determining unacceptable color alteration in composites $(13,17,18)$.

In the present study, Tetric Ceram presented the highest $\Delta \mathrm{b}$ values already in the first 8 -h aging cycle. This trend towards yellowing could be justified by the presence of residual camphorquinone in the composite (11). Even when used in small amounts, with percentages ranging from 0.03 to $0.1 \%$, it is a yellow color compound, which presents degradation in the course of time, promoting color alteration in the composite (19). In addition, tertiary amines (accelerators) form by-products derived from light activation, which cause yellowing of the material under the influence of light and heat (20), factors present during the AAA process. However, Z250, which also has camphorquinone in its composition, presented the lowest variation in $\Delta \mathrm{b}$. This difference between the two composites may have occurred due to the presence of TEGDMA in the formulation of Tetric Ceram. The monomer TEGDMA has greater predisposition to water sorption than UDMA, increasing the solubility of the polymer (21). Greater water sorption provides the composite with lower color stability, due to the increase in free volume of the formed polymer and, consequently, greater space for the water molecules to diffuse into the polymeric network, contributing to degradation of the material (6).

Furuse et al. (15) evaluated color alteration and brightness in silorane and dimethacrylate-based composites after different periods of accelerated artificial aging $(24,72,120$ and $192 \mathrm{~h})$. According to the authors, composites generally present a reduction in the values of $\mathrm{L}^{*}$ and $\mathrm{a}^{*}$, and increase in $\mathrm{b}^{*}$ after aging, however, it was observed that the silorane-based composite maintained the value of $b^{*}$, which means greater color stability over the course of time, when compared with dimethacrylate-based composites. Nevertheless, these findings do not corroborate the results of the present study, as the composite that presented the least variation for the coordinate $b^{*}$ was Z250, a dimethacrylate-based composite.

A reason for such results could be the variation in filler size $(0.01$ to $3.5 \mu \mathrm{m})$ of Z250. Larger fillers present a different degree of degradation than that of smaller fillers (18). Considering that color perception is directly related to the reflection of incident light on the composite, the greater the variety in particle size, the greater scattering of light beams and the greater the color stability of the material (18).

In addition, dental composites with a low 
concentration of fillers present greater color alteration (22). However, the results presented in this study do not confirm this information, considering that there was greater color alteration for the composite Tetric Ceram, with a higher percentage (78.6\%) of fillers in comparison with the other composites. The same occurred to Filtek P90 which, in spite of having a lower concentration of fillers $(55 \%)$, presented intermediate behavior as regards color stability.

According to Palin et al. (23), silorane-based composites showed good chemical stability when exposed to aqueous media, with low water sorption, low solubility and low diffusion coefficient. This could explain the good results for the material obtained by Furuse et al. (15), but not those obtained in the present stud study, since only two aging cycles were sufficient to promote color alteration above the acceptable level for Filtek P90.

Kopperud et al. (24) detected the presence of iodonium salt in the initiator system of silorane-based composites. Iodonium salt becomes active when exposed to light sources with wavelengths close to $300 \mathrm{~nm}$; that is, in the UV spectrum of light, the same present in the AAA system used in this study. Iodonium salt is then decomposed into excited iodonium, reacting with the tertiary amines present in the formulation of the composite, making it an efficient photoinitiator for polymerization (25). When these free radicals react with the remaining tertiary amines, occurs the subtraction of a proton, generating a new amine radical (25). The photo-chemically induced color alteration is attributed to oxidation of the accelerator amine, although discoloration by oxidation of the unreacted methacrylate groups is also considered (15). Therefore, if the use of iodonium salts increases the quantity of free amines, and considering that the photo-decomposition of camphoroquinone increases with the addition of amine (25), this could be understood as less color stability for silorane-based composites, according to the results of this study.

Despite the limitations of this study, the results allowed to conclude that the color alteration of composites begins as soon as the stimuli for their degradation are performed, and that these alterations are material-dependent, therefore accepting the tested hypothesis. Different periods of aging promoted different results for the optical properties of composites; however, further studies using different equipment and aging methods should be conducted in order to obtain the correct relationship between time of clinical use and degradation of composites.

\section{RESUMO}

O objetivo deste estudo foi avaliar estabilidade de cor de compósitos submetidos a diferentes períodos de envelhecimento artificial acelerado (EAA). Foram confeccionados, em matriz de teflon (10x2 mm), 24 corpos-de-prova de três compósitos $(\mathrm{n}=8)$ : Tetric Ceram (Ivoclar/Vivadent); Filtek P90 e Z250 (3M ESPE), cor A3. Após fotoativação por $20 \mathrm{~s}$ (FlashLite 1401), polimento e leitura inicial de cor (espectrofotômetro PCB 687; BYK Gardner), os corpos-de-prova foram submetidos ao EAA (C-UV, Comexim), com ciclos de $8 \mathrm{~h}: 4 \mathrm{~h}$ de exposições a raios UV-B a $50^{\circ} \mathrm{C}$ e $4 \mathrm{~h}$ de condensação a $50^{\circ} \mathrm{C}$. Ao final de cada ciclo, leituras de cor eram realizadas e quando o valor médio de $\Delta \mathrm{E}$ atingisse índice $\geq 3,30$, o ensaio era encerrado. Observou-se que Tetric Ceram apresentou alteração de $\Delta \mathrm{E}$ igual a 3,33 já no primeiro ciclo de envelhecimento. Com Filtek P90 foram necessários dois ciclos de $\mathrm{EAA}(\Delta \mathrm{E}=3,60)$ e para $\mathrm{Z} 250$ quatro $(\Delta \mathrm{E}=3,42)$. Observou-se que a cada ciclo ocorria diminuição na luminosidade de todas as amostras $(\Delta \mathrm{L})$. Concluiu-se que um curto período de EAA já é suficiente para que compósitos apresentem alteração de cor inaceitável clinicamente e que esta alteração é material dependente.

\section{REFERENCES}

1. Hahnel S, Henrich A, Bürgers R, Handel G, Rosentritt M. Investigation of mechanical properties of modern dental composites after artificial aging for one year. Oper Dent 2010;35:412-419.

2. Eick JD, Smith RE, Pinzino CS, Kostoryz EL. Stability of silorane dental monomers in aqueous systems. J Dent 2006;34:405-410.

3. Souza AB, Silame FD, Alandia-Roman CC, Cruvinel DR, Garcia Lda F, Pires-de-Souza Fde C. Color stability of repaired composite submitted to accelerated artificial aging. Gen Dent 2012;60:e321-e325.

4. Janda R, Roulet JF, Kaminsky M, Steffin G, Latta M. Color stability of resin matrix restorative materials as a function of the method of light activation. Eur J Oral Sci 2004;112:280-285.

5. Micali B, Basting RT. Effectiveness of composite resin polymerization using light-emitting diodes (LEDs) or halogenbased light-curing units. Braz Oral Res 2004;18:266-270.

6. Ferracane JL. Hygroscopic and hydrolytic effects in dental polymer networks. Dent Mater 2006;22:211-222.

7. Yap AUJ, Lee HK, Sabapathy R. Release of methacrylic acid from dental composites. Dent Mater 2000;16:172-179.

8. Imazato S, Tarumi H, Kato S, Ebisu S. Water sorption and colour stability of composites containing the antibacterial monomer MDPB. J Dent 1999;27:279-283.

9. Paravina RD, Ontiveros JC, Powers JM. Accelerated aging effects on color and translucency of bleaching-shade composites. J Esthet Restor Dent 2004;16:117-127.

10. Ferracane JL, Moser JB, Greener EH. Ultraviolet Lightinduced yellowing of dental restorative resins. J Prosthet Dent 1985;54:483-487.

11. Sarafianou A, Iosifidou S, Papadopoulus T, Eliades G. Color stability and degree of cure of direct composite restoratives after accelerated aging. Oper Dent 2007;32:406-411.

12. Kolbeck C, Rosentritt M, Lang R, Handel G. Discoloration of 
facing and restorative composites by UV-irradiation and staining food. Dent Mater 2006;22:63-68.

13. Pires-de-Souza Fde C, Casemiro LA, Garcia Lda F, Cruvinel DR. Color stability of dental ceramics submitted to artificial accelerated aging after repeated firings. J Prosthet Dent 2009;101:13-18.

14. Ruyter IE, Nilner K, Möller B. Color stability of dental composite resin materials for crown and bridge veneers. Dent Mater 1987;3:246-251.

15. Furuse AY, Gordon K, Rodrigues FP, Silikas N, Watts DC. Color-stability and gloss-retention of silorane and dimethacrylate composites with accelerated aging. J Dent 2008;36:945-952.

16. Mair LH. Staining of vivo subsurface degradation in dental composite with silver nitrate. J Dent Rest 1991;70:215-220.

17. Zanin FR, Garcia Lda F, Casemiro LA, Pires-de-Souza Fde C. Effect of artificial accelerated aging on color stability and surface roughness of indirect composites. Eur J Prosthodont Restor Dent 2008;16:10-14.

18. Pires-de-Souza Fde C, Garcia Lda F, Hamida HM, Casemiro LA. Color stability of composites subjected to accelerated aging after curing using either a halogen or light emitting diode source. Braz Dent J 2007;18:119-123.

19. Dlugokinski MD, Cauguman FW, Rueggeberg FA. Assessing the effect of extraneous light on photoactivated resin composites. J
Am Dent Assoc 1998;128:1103-1109.

20. Janda R, Roulet JF, Latta M, Steffin G, Ruttermann S. Color stability of resin-based filling materials after aging when cured with plasma or halogen light. Eur J Oral Sci 2005;113:251-257.

21. Kim JH, Lee YK, Powers JM. Influence of a series of organic and chemical substances on the translucency of resin composites. J Biomed Mater Res Part B: Appl Biomater 2006;77:21-27.

22. Schulze KA, Marshall SJ, Gansky SA, Marshall GW. Color stability and hardness in dental composites after accelerated aging. Dent Mater 2003;19:612-619.

23. Palin WM, Fleming GJ, Burke FJ, Marquis PM, Randall RC. The influence of short and medium-term water immersion on the hydrolytic stability of novel low-shrink dental composites. Dent Mater 2005;21:852-863.

24. Kopperud HM, Schmidt M, Kleven IS. Elution of substances from a silorane-based dental composite. Eur J Oral Sci 2010;118:100102.

25. Ogliari FA, Ely C, Petzhold CL, Demarco FF, Piva E. Onium salt improves the polymerization kinetics in an experimental dental adhesive resin. J Dent 2007;35:583-587.

Received November 2, 2011 Accepted August 21, 2012 